\title{
Barriers to surveillance imaging adherence in early-staged lung cancer
}

\author{
Ian C. Bostock^, Wayne Hofstetter, Reza Mehran, Ravi Rajaram, David Rice, Boris Sepesi, \\ Stephen Swisher, Ara Vaporciyan, Garrett Walsh, Mara B. Antonoff \\ Department of Thoracic and Cardiovascular Surgery, The University of Texas MD Anderson Cancer Center, Houston, TX, USA \\ Contributions: (I) Conception and design: IC Bostock, MB Antonoff; (II) Administrative support: None; (III) Provision of study materials or patients: \\ None; (IV) Collection and assembly of data: None; (V) Data analysis and interpretation: IC Bostock, MB Antonoff; (VI) Manuscript writing: All \\ authors; (VII) Final approval of manuscript: All authors. \\ Correspondence to: Mara B. Antonoff, MD, FACS. Associate Professor, Department of Thoracic and Cardiovascular Surgery, University of Texas MD \\ Anderson Cancer Center, 1515 Holcombe Blvd, Houston, TX 77030, USA. Email: mbantonoff@mdanderson.org.
}

\begin{abstract}
Background: Frequency of post-treatment surveillance is highly variable following curative resection of non-small cell lung cancer (NSCLC). We sought to characterize surveillance practices after lobectomy for early-stage NSCLC and to identify the impact of various demographic factors on patterns of surveillance.

Methods: We included patients who underwent anatomic lobectomy for pathologic stage I NSCLC from 2007-2017. Demographic characteristics, post-operative imaging studies (internal and external), and travel distance were recorded. We defined the minimal standard of surveillance imaging studies (MSSIS) as $\geq 7$ studies in the first 5 years (computed tomography/positron emission tomography). Patient sex, ethnicity, marital status, and distance traveled were evaluated as predictors of imaging receipt. Standard descriptive statistics, univariate, and multivariate analysis (MVR) were performed.

Results: A total of 1,288 patients were included. The mean age was $65.5 \pm 10.1$ years, $589(45.7 \%)$ were male, 1,081 (83.9\%) were Caucasian, and 924 (71.7\%) were married. Only 464 (36\%) achieved MSSIS; being married [75.6\% (351/464) vs. 68.8\% (567/824), $\mathrm{P}=0.01]$ and having larger tumor size $(2.63 \pm 0.04$ vs. $2.49 \pm 0.05 \mathrm{~cm}, \mathrm{P}=0.03)$ were both associated with MSSIS. Patients residing $<100$ miles from the hospital were more likely to have MSSIS, and more imaging at 24 months (4.1 \pm 2.2 vs. $3.7 \pm 2.0 ; \mathrm{P}=0.006), 60$ months $(8.0 \pm 5.1$ vs. $6.6 \pm 4.2, \mathrm{P}=0.001)$ and overall $(10 \pm 7.3$ vs. $8.2 \pm 6.3 ; \mathrm{P}=0.001)$. On $\mathrm{MVR}$, tumor size and marital status were associated with MSSIS.

Conclusions: Two-thirds of patients at our institution did not undergo recommended surveillance imaging. Tumor size, being married, and living $<100$ miles from the medical center were associated with an increased number of imaging studies and greater adherence to guidelines.
\end{abstract}

Keywords: Early-stage lung cancer; surveillance imaging; imaging guidelines; survivorship care; surveillance guidelines

Submitted Jul 30, 2021. Accepted for publication Sep 23, 2021.

doi: $10.21037 /$ jtd-21-1254

View this article at: https://dx.doi.org/10.21037/jtd-21-1254

\section{Introduction}

Approximately 50,000 patients undergo surgical treatment of early stage lung cancer in the United States each year (1). The use of computed tomography (CT) and positron- emission tomography (PET) scans has become a standard part of the diagnostic and post-treatment surveillance strategies in patients with lung cancer (2-7). These imaging studies are routinely used to monitor for recurrence,

\footnotetext{
^ ORCID: 0000-0002-6912-0970.
} 
response to therapy, and disease progression. Several organizations devoted to the care of patients with lung cancer have established guidelines for routine postoperative surveillance with the use of cross-sectional imaging at specified intervals after resection (5-11).

The primary premise supporting the practice of posttreatment surveillance is that the timely detection of disease recurrence or a second primary lung cancer facilitates prompt intervention and therefore improved subsequent disease survival. There exists substantial variability among the recommendations of different guidelines, ranging from routine clinic visits with or without imaging, chest radiographs at 3 and 6 months, or semiannual chest CT scans after resection $(5,6,9-11)$. In general, postoperative imaging evaluation is recommended to occur more frequently in the first 2 years after surgery, when recurrence risk is felt to be greatest. Whether these surveillance strategies have translated into meaningful improvements in lung cancer specific oncologic outcomes remains controversial (7,12-15).

There is a paucity of data with regard to specific patientand system-related barriers for the implementation and adherence of surveillance imaging guidelines after surgical treatment of early stage lung cancer. We sought to characterize patterns of surveillance after anatomic lobectomy for pathologic stage I non-small cell lung cancer (NSCLC) at our institution and to identify the impact of various demographic factors on patterns of surveillance. We hypothesized that sociological and demographic traits may render some subgroups of patients to be at higher risk of delayed or missed surveillance imaging visits.

We present the following article in accordance with the STROBE reporting checklist (available at https://dx.doi. org/10.21037/jtd-21-1254).

\section{Methods}

After obtaining institutional review board approval (protocol PA17-0765, approved 10/03/2017), the Thoracic and Cardiovascular Surgery Departmental database at MD Anderson Cancer Center was queried for all pathologic stage I NSCLC patients (TNM $8^{\text {th }}$ edition) who underwent lobectomy from 2007 to 2017. Charts were reviewed, and demographic characteristics and surveillance details were captured. We reviewed the number of imaging studies performed after surgery, including both internal and external studies. The study was conducted in accordance with the Declaration of Helsinki (as revised in 2013). Due to the retrospective nature of our data review, informed consent was not obtained.

Patients were categorized based on distance traveled from their homes to the institution and placed into two groups: $<100 v s . \geq 100$ miles. The distance variable was classified in this manner in order to effectively capture out of state patients. Since the majority of the patients cared for at our Institution (about 70\%) live in the state of Texas, this distance could be reflective of a more rural environment or at least a barrier to return to our facility for survivorship care.

We defined the minimal standard of surveillance imaging studies (MSSIS) as obtaining at least 7 studies in the first 5 years after resection (CT and/or PET-CT studies). We strive, at minimum, to see patients every 6 months for the first 2 years and then yearly for the next 3 years, recognizing that some patients deemed to be at higher risk of recurrence based may be followed initially every 3 months. Crosssectional imaging, typically consisting of a CT chest, accompanies each of these visits. This is our institutional protocol and has been consistent throughout the study period. The patients who were lost to follow up were included in the no MSSIS groups and analyzed accordingly.

At our institution, patients are usually followed using phone, email, and "My Chart" (web based application in our electronic medical record, Epic). We send frequent reminders to all patients regarding upcoming testing and appointments. Additionally, we have a robust survivorship department that is in charge of ensuring adequate follow up for patients.

We assessed the impact of gender, ethnicity, marital status, and distance from hospital on patterns of posttreatment surveillance. Due to the retrospective nature of our data review, informed consent was not obtained.

\section{Statistical analysis}

Statistical analysis was performed using SPSS 16 Software (IBM Corporation, 1 New Orchard Road, Armonk, NY, USA). Student's $t$-tests were used for the analysis of continuous variables with a normal distribution. Chisquared or Mann-Whitney tests were used for univariate analysis of categorical variables. For this analysis, a forward stepwise multivariate logistic regression model was created using MSSIS as the dependent variable and an entry threshold of $\mathrm{P}<0.05$ for entry of potential predictor variables into the model. Potential predictor variables for this model included the preoperative and intraoperative patient- and procedure-related variables. Kaplan-Meier survival analysis was utilized to estimate all-cause mortality. Statistical significance was accepted at $\mathrm{P}<0.05$. 
Table 1 Univariate analysis of variables associated with obtaining minimal standard of surveillance imaging studies (MSSIS) after resection of early-stage lung cancer

\begin{tabular}{|c|c|c|c|}
\hline Variables & No MSSIS $(n=824)$ & MSSIS $(n=464)$ & $P$ value \\
\hline Gender (male), n (\%) & $377(45.8)$ & $208(44.8)$ & 0.75 \\
\hline Caucasian, n (\%) & $701(85.1)$ & $395(85.1)$ & 0.83 \\
\hline Tumor size $(\mathrm{cm})$, mean $\pm \mathrm{SD}$ & $2.49( \pm 1.01)$ & $2.63 \pm 1.09$ & 0.03 \\
\hline$>100$ miles group, $\mathrm{n}(\%)$ & 487 (59.2) & $233(50.9)$ & 0.02 \\
\hline Married, n (\%) & $567(68.8)$ & $351(75.6)$ & 0.01 \\
\hline Thoracoscopy, n (\%) & 406 (49.3) & $253(54.5)$ & 0.1 \\
\hline Stage IA, n (\%) & $479(58.1)$ & 241 (51.9) & 0.05 \\
\hline
\end{tabular}

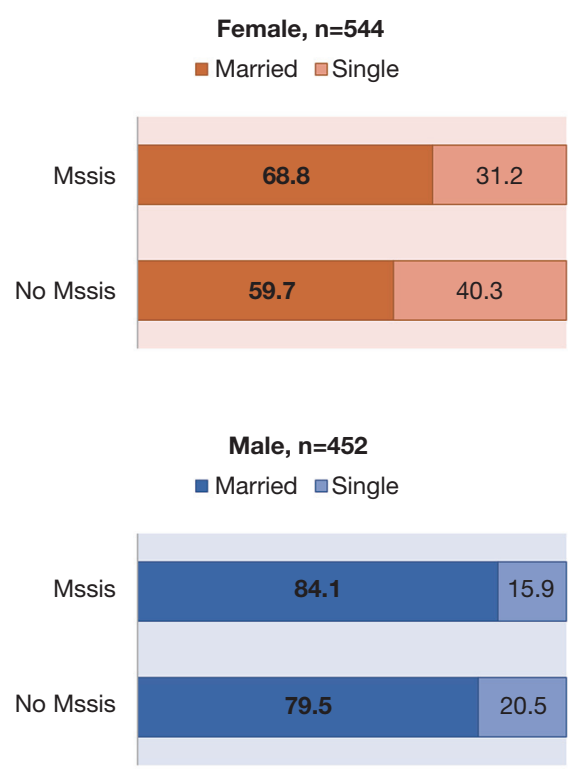

Figure 1 Subgroup analysis of patients in the minimal standard of surveillance imaging studies group (MSSIS) and no MSSIS groups stratified by marital status.

\section{Results}

\section{Patients}

A total of 1,288 patients met inclusion criteria (Table 1). The mean age at time of surgery was $65.5 \pm 10.1$ years, 589 (45.7\%) patients were male, 1,081 (83.9\%) were Caucasian, and $924(71.7 \%)$ were married.

\section{Surveillance}

The mean follow-up period for this cohort was $54.2 \pm 36.4$ months (median 49.3 months), during which time the average number of surveillance imaging studies was $9.0 \pm 6.8$ (range, 1-44). Among all patients, only $36 \%$ $(464 / 1,288)$ patients achieved MSSIS and in patients alive for more than 5 years, $68.4 \%$ (270/395) achieved MSSIS.

\section{Predictors of appropriate surveillance:}

On univariate analysis, likelihood of achieving MSSIS was not predicted by age, gender, ethnicity, or receipt of minimally invasive procedure (Table 1). Being married [75.6\% (351/464) vs. 68.8\% (366/537); $\mathrm{P}=0.02]$ and a larger tumor size $(2.63 \pm 0.04$ vs. $2.49 \pm 0.05 \mathrm{~cm}, \mathrm{P}=0.03,95 \%$ CI: 1.03-1.31) were associated with a greater likelihood of MSSIS (Table 1).

Subgroup analysis in patients that were married and obtained MSSIS showed that $68.8 \%$ of married women obtained MSSIS in comparison to $84.1 \%$ of married men. Furthermore, women who did not obtain MSSIS and were married accounted for $59.7 \%$ in comparison to $79.5 \%$ of married men who did not obtain MSSIS (Figure 1).

Overall, the patients residing $<100$ miles from the hospital were more likely to have appropriate surveillance than those residing $>100$ miles $(10 \pm 7.3$ vs. $8.2 \pm 6.3$; 


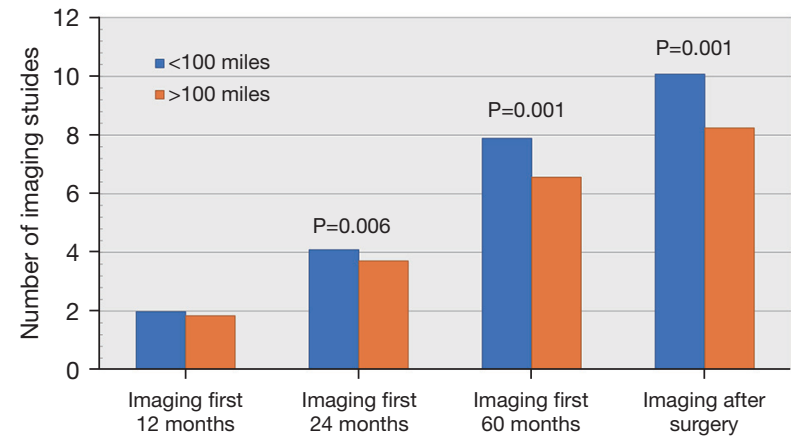

Figure 2 Number of imaging studies obtained in patients that resided $<100$ miles and $>100$ miles from our Institution in the first 12 months, 24 months, 60 months, and total, postoperatively after resection of early-stage lung cancer.

$\mathrm{P}=0.001)$. There was no difference in the frequency of postoperative imaging between the patients in the $<100$ miles and $>100$ miles groups in the first 12 months (2.0 \pm 1.4 vs. $1.8 \pm 1.3 ; \mathrm{P}=0.09)$. However, those patients living closer to the institution underwent more imaging studies in the first $24(4.1 \pm 2.2$ vs. $3.7 \pm 2.0 ; \mathrm{P}=0.006)$ and 60 months postoperatively than those living further away (8.0 05.1 vs. $6.6 \pm 4.2, \mathrm{P}=0.001$; Figure 2). These findings suggest that initial surveillance practices start out similar between these two groups, but that those patients who have to travel further have a greater tendency to fall off of the recommended surveillance course with time.

On multivariate analysis, tumor size $(\mathrm{OR}=0.87,95 \%$ CI: $0.77-0.99 ; \mathrm{P}=0.001)$ and marital status $(\mathrm{OR}=0.65,95 \%$ CI: $0.49-0.87 ; \mathrm{P}=0.003$ ) were confirmed to be associated with obtaining MSSIS (Table 2). Distance from the hospital showed a tendency towards statistical significance, as well $(\mathrm{P}=0.06)$.

There was no difference in overall survival between the patients that obtained MSSIS compared to those who did not $(78 \%$ vs. $75 \% ; \mathrm{P}=0.34)$ with a mean follow up period of $54.2 \pm 36.3$ months.

\section{Discussion}

In this study, which evaluated a homogenous group of more than 1,200 patients who underwent lobectomy for pathologic stage I NSCLC at a single institution, we demonstrated several important findings. Disappointingly, only barely over a third of all patients received minimal expected imaging studies for surveillance in the first five years after surgery. In addition, we showed that there are
Table 2 Multivariate logistic regression model with variables associated with obtaining minimal standard of surveillance imaging studies (MSSIS) after resection of early-stage lung cancer

\begin{tabular}{llll}
\hline Variables & OR & $95 \% \mathrm{Cl}$ & $\mathrm{P}$ value \\
\hline Tumor size & 0.87 & $0.77-0.99$ & 0.02 \\
Distance to Institution & 1.01 & $0.99-1.00$ & 0.06 \\
Married & 0.65 & $0.49-0.87$ & 0.003 \\
\hline
\end{tabular}

sociological risk factors that render patients less likely to receive adequate surveillance, specifically with regard to marital status and location of residence relative to the medical center. These findings are important as we contemplate strategies to ensure that all patients receive high quality and equitable cancer care through all stages of treatment and survivorship.

In a study reported by Sharma et al., the use of CT and PET imaging for surveillance after curative-intent surgical resection of early-stage lung cancer increased from $13.7 \%$ to $57.3 \%$ in the United States between 1997 and 2005 (4). While it is reassuring that cross-sectional imaging surveillance is on the rise, findings by Sharma, which are corroborated by our results herein, clearly show that there is room for improvement overall, and specifically with regard to certain patient subgroups. These persistently disappointing numbers may be explained by a potential under capturing of the imaging obtained outside of the primary health system, to lower adherence to surveillance guidelines in the community, or to inadequate understanding of the overall benefits and rationale for ongoing surveillance.

In a prior study of Medicare beneficiaries treated curatively for NSCLC, the investigators found that $61.4 \%$ of patients received guideline-adherent surveillance during the first 2 years after treatment (which included surgical as well as nonsurgical therapies) (16). The reported rates of CT and PET scans in the first year after treatment were $78.5 \%$ and $28.9 \%$, respectively. Adherence with surveillance imaging was associated with younger age, higher income, more comorbidities, access to primary care, and receipt of SBRT as the primary treatment modality (16).

In our study population, we did not find MSSIS to be associated with age, sex, ethnicity, or operative approach. However, we did find that MSSIS was associated with living closer to the hospital. Further, those patients who lived closer to the hospital were more likely to have greater numbers of imaging studies in the first 2 and 5 years 
after surgery. This is an important finding, as previous studies have reported a marked decrease in adherence to surveillance guidelines after the first 2 years from surgical resection (16), and we have found this to be specifically true in patients who live further from the hospital. Strategies to optimize access to local imaging centers as part of the preoperative or survivorship planning may help improved adherence to surveillance guidelines long-term.

In our study, we found that patients who were married had a greater likelihood of MSSIS, potentially affecting their long-term oncologic outcomes. Prior reports in the literature have described the association of marital status on oncologic outcomes for different solid tumors. For example, in a recent study by Zhang et al. on patient with gastric adenocarcinoma, married patients had a better 5 -year OS (32.09\% vs. $24.61 \%, \mathrm{P}<0.001)$ and 5 -year cancer-specific survival (CSS) $(37.74 \%$ vs. $32.79 \%, \mathrm{P}<0.001)$ than their unmarried counterparts. The authors hypothesized that these observations could be explained by undertreatment and lack of social support in unmarried patients (17). Further, in a population based study describing the effect of martial status on lung cancer patients in Belgium, both men and women appeared to benefit from being in a relationship with a highly-educated partner. Men appeared to benefit the most from the educational level of their partner and women benefited more by their housing conditions (18); one could hypothesize that interventions to target specific high risk groups, such as single cancer survivors, would be beneficial.

Even though our study did not find a difference in the frequency of surveillance imaging with regards to ethnicity, previous reports in the literature have found a lower 5-year survival between 2004 and 2009 in black patients compared to white patients with lung cancer ( $14.9 \%$ vs. $19.4 \%)$ $(19,20)$. To our knowledge, the frequency of surveillance imaging in specific subgroups has not been specifically evaluated and should be considered a priority for quality improvement initiatives to help address health disparities and standardize cancer follow up in the population. Moreover, we recognize that the benefits of early detection are manifest in numerous other ways, such as extent and modality of treatment required. Ultimately, we believe that our study is relevant to the existing literature as it provides a foundation for understanding disparities in postoperative follow-up, and it justifies further investigations in survivorship care. Furthermore, an area that has lately shown to have a tremendous potential in survivorship care is telemedicine, which may provide a means to bridge travel distance, poor patient adherence, and facilitate access to care (20). Furthermore, additional ways to improving the frequency of surveillance imaging could to be to strengthen relationships with different medical centers around the country, more collaborative electronic medical record platforms, and optimizing patient education. Ultimately, in order to improve surveillance compliance, we need to understand the barriers, and thus, a needs assessment would be very helpful to clarify the challenges faced by patients who travel further.

The findings of this study should be interpreted in the setting of several limitations. Given the retrospective nature of the data, comparisons of the study groups can suffer from some degree of bias. Theoretically, patients could have been seen outside of our institution by other local physicians accounting for a degree of under capturing. Nonetheless, it is our practice to have thorough involvement in survivorship follow-up and studies performed by other institutions are routinely captured and screened into our system.

We accounted for CT scans of the chest or PETCT performed after the date of operation. If the patient underwent an additional CT chest after their operation for a different reason, this would increase their surveillance imaging number per our methodology. We were not able to elucidate the indication for imaging from these data. We recognize that for some patients, this may introduce some confounding factors but believe that in general, we are capturing surveillance scans for patients with early stage lung cancer.

Overall, patients lost to follow up were considered as having no imaging after surgery. It is possible that the patients were obtaining imaging elsewhere and were not captured by our system but we believe that this event would be rare given the way survivorship care is handled at our institution. Despite these limitations, we believe that this study has the strengths of a rigorously maintained database and yields strong, generalizable results.

\section{Conclusions}

Importantly, we have shown that, despite well-established surveillance guidelines, two-thirds of patients do not receive appropriate imaging at our institution. Tumor size, being married, and living $<100$ miles from the medical center were associated with an increased number of imaging studies in the first 5 years and greater adherence to standards for surveillance. Further investigations to elucidate predictors of inadequate surveillance and survivorship strategies are needed, as well as efforts to address such barriers as they are 
identified.

Future directions for this project include using travel distance and local zip code data to analyze the influence of socioeconomic status on adherence to surveillance guidelines.

\section{Acknowledgments}

The paper was presented virtually at the STS 2021 Annual Meeting.

Funding: None.

\section{Footnote}

Reporting Checklist: The authors have completed the STROBE reporting checklist. Available at https://dx.doi. org/10.21037/jtd-21-1254

Data Sharing Statement: Available at https://dx.doi. org/10.21037/jtd-21-1254

Peer Review File: Available at https://dx.doi.org/10.21037/ jtd-21-1254

Conflicts of Interest: All authors have completed the ICMJE uniform disclosure form (available at https://dx.doi. org/10.21037/jtd-21-1254). MBA serves as an unpaid editorial board member of Fournal of Thoracic Disease from August 2019 to July 2021. The other authors have no conflicts of interest to declare.

Ethical Statement: The authors are accountable for all aspects of the work in ensuring that questions related to the accuracy or integrity of any part of the work are appropriately investigated and resolved. The study was conducted in accordance with the Declaration of Helsinki (as revised in 2013). Institutional Review Board Approval was obtained (PA17-0765, approved 10/03/2017). Due to the retrospective nature of our data review, informed consent was not obtained.

Open Access Statement: This is an Open Access article distributed in accordance with the Creative Commons Attribution-NonCommercial-NoDerivs 4.0 International License (CC BY-NC-ND 4.0), which permits the noncommercial replication and distribution of the article with the strict proviso that no changes or edits are made and the original work is properly cited (including links to both the formal publication through the relevant DOI and the license). See: https://creativecommons.org/licenses/by-nc-nd/4.0/.

\section{References}

1. Farjah F, Wood DE, Yanez D 3rd, et al. Temporal trends in the management of potentially resectable lung cancer. Ann Thorac Surg 2008;85:1850-5; discussion 1856.

2. Chiu $\mathrm{CH}, \mathrm{Chern} \mathrm{MS}, \mathrm{Wu} \mathrm{MH}$, et al. Usefulness of low-dose spiral CT of the chest in regular follow-up of postoperative non-small cell lung cancer patients: Preliminary report. J Thorac Cardiovasc Surg 2003;125:1300-5.

3. Cho S, Lee EB. A follow-up of integrated positron emission tomography/computed tomography after curative resection of non-small-cell lung cancer in asymptomatic patients. J Thorac Cardiovasc Surg 2010;139:1447-51.

4. Sharma G, Nishi SP, Lin YL, et al. Pattern of Imaging after Lung Cancer Resection. 1992-2005. Ann Am Thorac Soc 2016;13:1559-67.

5. Rubins J, Unger M, Colice GL, et al. Follow-up and surveillance of the lung cancer patient following curative intent therapy: ACCP evidence-based clinical practice guideline (2nd edition). Chest 2007;132:355S-67S.

6. Sause WT, Byhardt RW, Curran WJ Jr, et al. Followup of non-small cell lung cancer. American College of Radiology. ACR Appropriateness Criteria. Radiology 2000;215 Suppl:1363-72.

7. Smith TJ. Evidence-based follow-up of lung cancer patients. Semin Oncol 2003;30:361-8.

8. D'Addario G, Felip E; ESMO Guidelines Working Group. Non-small-cell lung cancer: ESMO clinical recommendations for diagnosis, treatment and follow-up. Ann Oncol 2009;20 Suppl 4:68-70.

9. Abdollah F, Sun M, Suardi N, et al. National Comprehensive Cancer Network practice guidelines 2011: Need for more accurate recommendations for pelvic lymph node dissection in prostate cancer. J Urol 2012;188:423-8.

10. Bjegovich-Weidman $M$, Haid M, Kumar S, et al. Establishing a community-based lung cancer multidisciplinary clinic as part of a large integrated health care system: aurora health care. J Oncol Pract 2010;6:e27-30.

11. Felip E, Stahel RA, Pavlidis N, et al. ESMO Minimum Clinical Recommendations for diagnosis, treatment and follow-up of non-small-cell lung cancer (NSCLC). Ann Oncol 2005;16 Suppl 1:i28-9.

12. Edelman MJ, Schuetz J. Follow-up of local (stage I and 
stage II) non-small-cell lung cancer after surgical resection. Curr Treat Options Oncol 2002;3:67-73.

13. Lamont JP, Kakuda JT, Smith D, et al. Systematic postoperative radiologic follow-up in patients with nonsmall cell lung cancer for detecting second primary lung cancer in stage IA. Arch Surg 2002;137:935-8; discussion 938-40.

14. Walsh GL, O'Connor M, Willis KM, et al. Is follow-up of lung cancer patients after resection medically indicated and cost-effective? Ann Thorac Surg 1995;60:1563-70; discussion 1570-2.

15. Younes RN, Gross JL, Deheinzelin D. Follow-up in lung cancer: how often and for what purpose? Chest 1999; 115:1494-9.

16. Erb CT, Su KW, Soulos PR, et al. Surveillance Practice Patterns after Curative Intent Therapy for Stage I NonSmall-Cell Lung Cancer in the Medicare Population.

Cite this article as: Bostock IC, Hofstetter W, Mehran R, Rajaram R, Rice D, Sepesi B, Swisher S, Vaporciyan A, Walsh $\mathrm{G}$, Antonoff MB. Barriers to surveillance imaging adherence in early-staged lung cancer. J Thorac Dis 2021;13(12):6848-6854. doi: $10.21037 /$ jtd-21-1254
Lung Cancer 2016;99:200-7.

17. Zhang J, Gan L, Wu Z, et al. The influence of marital status on the stage at diagnosis, treatment, and survival of adult patients with gastric cancer: a population-based study. Oncotarget 2017;8:22385-405.

18. Vanthomme K, Vandenheede H, Hagedoorn P, et al. Socioeconomic disparities in lung cancer mortality in Belgian men and women (2001-2011): does it matter who you live with? BMC Public Health 2016;16:493.

19. Richards TB, Henley SJ, Puckett MC, et al. Lung cancer survival in the United States by race and stage (2001-2009): Findings from the CONCORD-2 study. Cancer 2017;123 Suppl 24:5079-99.

20. Dingemans AC, Soo RA, Jazieh AR, et al. Treatment Guidance for Patients With Lung Cancer During the Coronavirus 2019 Pandemic. J Thorac Oncol 2020;15:1119-36. 